\title{
THERMOTHERAPY EFFECTIVE AND SAFER THAN MILTEFOSINE IN THE TREATMENT OF CUTANEOUS LEISHMANIASIS IN COLOMBIA
}

\author{
Liliana LÓPEZ(1), Claudia CRUZ(2), Gonzalo GODOY(2), Sara M. ROBLEDO(1) \& Iván D. VÉLEZ(1)
}

\begin{abstract}
SUMMARY
In Colombia, pentavalent antimonials and miltefosine are the drugs of choice for the treatment of cutaneous leishmaniasis; however, their toxicity, treatment duration, (treatment adherence problems), cost, and decreased parasite sensitivity make the search for alternative treatments of American cutaneous leishmaniasis necessary. Based on the results found in a controlled, open, randomized, phase III clinical trial, the efficacy and safety of miltefosine was compared to that of thermotherapy for the treatment of cutaneous leishmaniasis in Colombia. Adult patients from the Colombian army participated in the study; they received either $50 \mathrm{mg}$ of miltefosine three times per day for 28 days by the oral route $(n=145)$ or a thermotherapy (Thermomed $\left.{ }^{\circledR}\right)$ application of $50{ }^{\circ} \mathrm{C}$ for 30 seconds over the lesion and surrounding area $(\mathrm{n}=149)$. Both groups were comparable with respect to their sociodemographic, clinical, and parasitological characteristics. The efficacy of miltefosine by protocol and by intention to treat was $70 \%(85 / 122$ patients) and $69 \%$ (85/145 patients), respectively. The adverse effects were primarily gastrointestinal for miltefosine and pain at the lesion site after treatment for thermotherapy. No statistically significant difference was found in the efficacy analysis (intention to treat and protocol) between the two treatments. ClinicalTrials.gov: NCT00471705.
\end{abstract}

KEYWORDS: Thermotherapy; Cutaneous leishmaniasis; Miltefosine; Treatment; Efficacy; Safety.

\section{INTRODUCTION}

Leishmaniasis is a disease produced by parasites of the genus Leishmania; it is transmitted by female insects of the genus Lutzomyia in the Americas or Phlebotomus in the Old World, and it affects humans and domesticated and wild mammals ${ }^{2,4,17}$. It is endemic in over 95 countries, the majority of which are classified as developing. It is estimated that worldwide, around 12 million individuals are infected with Leishmania ${ }^{35}$. Cutaneous Leishmaniasis (CL) is the clinical manifestation presented by the majority of cases around the world, and there is approximately 1 to 1.5 million new cases every year ${ }^{2,17,35}$. In Colombia, a re-emergence of leishmaniasis has been seen since 2005, making the country second in the Americas for highest number of cases. From 2005-2008, there were 61,120 cases diagnosed, of which $34,262(56.1 \%)$ occurred in military personnel of the National Army.

Since the 1940's, pentavalent antimonials (meglumine antimoniate and sodium stibogluconate) have been the drug of choice for the treatment of CL; however, their toxicity, treatment period of 20 days that leads to treatment adherence issues, high cost, and progressively decreasing therapeutic response make necessary the search for alternative treatments ${ }^{8,27}$.

In the search for therapeutic alternatives, various oral medications have been evaluated, such as dapsone ${ }^{18}$, ketoconazole ${ }^{12,21}$, mefloquine ${ }^{9}$, and allopurinol ${ }^{31}$, none of which were shown to be adequately effective. An additional difficulty in the interpretation of results of clinical trials is the lack of methodological unity, which hinders their comparison ${ }^{3,8}$.

Miltefosine (hexadecylphosphocholine) is an oral medication initially developed as an anti-tumoral agent ${ }^{28}$ that later showed in vitro and in vivo activity against Leishmania $\mathrm{spp}^{5,6,15,28,37}$. In India, where resistance to antimonial agents is very high, miltefosine has been used since 1998 for the treatment of Visceral Leishmaniasis (VL) produced by $L$. donovani ${ }^{7,24}$. This has motivated its evaluation for the treatment of other leishmaniasis ${ }^{25}$. In Colombia, two studies have been conducted for the treatment of CL. The first is a phase I-II study with a reported cure rate by protocol of $66 \%$ in individuals who received a dose of 50$100 \mathrm{mg} /$ day and of $95 \%$ in individuals who received a dose of 133-150 $\mathrm{mg} / \mathrm{day}^{23}$. The second study was a multicenter study (Colombia and Guatemala) where miltefosine was compared against a placebo; this study showed contradictory results. In Colombia, the cure rate by protocol was $91 \%$, but in Guatemala, the rate was $53 \%$. Even though the sample size was small and the number of strains very small, the difference in the therapeutic response between both countries was attributed to the predominant Leishmania species of each country: Leishmania (Viannia) panamensis in Colombia, but L. (V.) braziliensis and L. (L.) mexicana in Guatemala. However, recent studies conducted in Colombia show

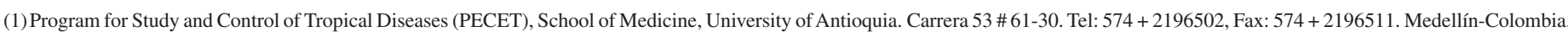
(2) Dirección de Sanidad, DISAN, Ejército de Colombia Carrera 7 \# 52-45. Tel: $571+347$ 0200, Fax: $571+3465527$ ext 152 . Bogotá-Colombia.

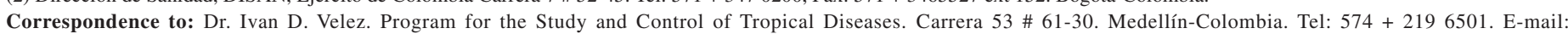
idvelez@pecet-colombia.org 


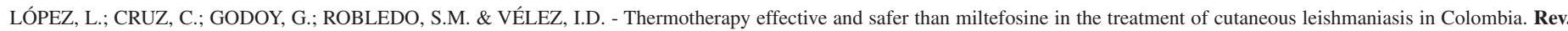
Inst. Med. Trop. Sao Paulo, 55(3): 197-204, 2013.

that $L .(V$.$) braziliensis and L .(V$.$) panamensis are the two species that$ produce the majority of cases in Colombia and that they occur in a similar proportion; however, $L$. (V.) panamensis predominates in the northeast of the country (Andean region) and $L$. (V.) braziliensis predominates in the southeast (PECET. Unpublished data). Based on the previous study, the Ministry of Social Security of Colombia authorized the registry and use of miltefosine, and it has been used for the treatment of different clinical forms of leishmaniasis.

On the other hand, studies conducted in different countries have shown that the localized application of heat by using Thermomed ${ }^{\circledR}$ equipment may achieve a cure rate that varies from 70 to $94 \%$. The Thermomed $^{\circledR}$ is an operator, with special devices which achieve and maintain a temperature of $50{ }^{\circ} \mathrm{C}$. The electrodes are placed locally in the lesion for 30 seconds, the device produces heat waves through radio frequency technology, which extends them to deeper layers of the skin, causing destruction of the amastigotes ${ }^{10,11,16,19,30}$. In Colombia, there has only been one report of the use of thermotherapy in the treatment of CL in a study that focused on patients with an L. guyanensis from the Andean region; however, the elevated number of participant follow-up losses $(81 \%)$ decreased the power of the study and did not allow for a conclusive efficacy result ${ }^{29}$.

This data analysis from a controlled phase III clinical trial was conducted with the aim of comparing the efficacy and safety of miltefosine with that of a single thermotherapy application in the treatment of CL in Colombia. The trial evaluated the efficacy and safety of miltefosine and thermotherapy as compared to meglumine antimoniate for the treatment of cutaneous leishmaniasis.

\section{MATERIALS AND METHODS}

Study design. The study was an open, randomized, phase III clinical trial, in which the efficacy and safety of miltefosine and thermotherapy were compared. Register ClinicalTrials.gov: code number NCT00471705.

Population and study site. The study was conducted between June 2006 and April 2008. The study subjects were adult males who were part of the Colombian army. The study was conducted at five military health care establishments located in the northeast, center, and south of Colombia.

Inclusion criteria. Patients who were included had: a) a confirmed parasitological diagnosis of leishmaniasis; b) no previous history of receiving treatment for the current infection; c) normal renal, hepatic, pancreatic, and hematologic tests; and d) voluntarily accepted participation in this study.

Exclusion criteria. Patients with a) serious concomitant diseases; b) lesions with mucosal involvement; c) 10 or more cutaneous lesions and a negative Montenegro test; and/or d) cutaneous lesions located less than $2 \mathrm{~cm}$ from the nasal, oral, lip border, eyes, urogenital orifice, and/ or anal mucosa.

Interventions. Miltefosine (Impavido ${ }^{\circledR}$, Zentaris Frankfurt-Germany) in a $50 \mathrm{mg}$ capsule was administered orally three times per day after meals for 28 days for a total dose of $4,200 \mathrm{mg}$ per patient. A single thermotherapy (Thermomed ${ }^{\circledR}$, Thermosurgery inc. Phoenix-USA) session was administered, consisting of applications at $50{ }^{\circ} \mathrm{C}$ over the lesion and surrounding areas for 30 seconds with prior asepsis and local $2 \%$ lidocaine anesthesia without epinephrine. The number of applications depended on the lesion size, and each time, heat was applied to the entire lesion area. Following thermotherapy, an antibiotic ointment (fucidic acid) was applied to the lesions and dressed with sterile gauze to prevent secondary infections over the next 10 days.

Data collection, clinical samples, and strain identification of Leishmania. After signing voluntary participation consent, all of the patients were assigned a clinical record with demographic information, lesion data, and review of inclusion/exclusion criteria. A photographic registry of all the lesions was obtained, and clinical samples were taken for the identification of Leishmania species via PCR-RFLP, following previously published protocols ${ }^{13,20}$.

Treatment group assignment. Assignment to each treatment group was randomized. A list of randomly generated treatments, in blocks of eight, was made (EpiInfo 3.1). Only the study coordinator had access to the list and was in charge of assigning the treatments.

Follow-up and outcome. During the study, the participants who received miltefosine were evaluated by research personnel at the beginning, middle (day 15), and end of treatment (day 29), as well as six weeks, three months, and six months post treatment. Patients who received thermotherapy were evaluated at the beginning, day 10 , and day 20 , as well as six weeks, three months, and six months post treatment. Renal, hepatic, pancreatic, and hematologic function tests were obtained before treatment, in the middle, and at the end of treatment. Evaluation of adverse events was conducted based on the usual criteria for the evaluation of adverse reactions in cancer therapy v.3 (CTCAE) ${ }^{26}$.

Response to treatment was clinically evaluated. The following definitions were used for each lesion:

Initial cure: Complete re-epithelization of all ulcers and the complete disappearance of induration up to three months following the termination of treatment.

Definitive cure: Initial cure plus the absence of recurrence at six months after completing treatment.

Treatment failure: a) Increase in lesion size greater than $50 \%$ by the end of treatment; b) Absence of clinical response at six weeks, which is a decrease in the lesion area to less than $50 \%$ upon final treatment evaluation; c) any sign of lesion activity at three months after completing treatment; or d) development of mucosal leishmaniasis (ML).

Relapse: Reactivation of the lesion at the original site after scar formation.

Rescue therapy for all participants who experienced treatment failure was the administration of meglumine antimoniate (Glucantime ${ }^{\circledR}$, Aventis, Paris, France) with a dose of $20 \mathrm{mg} / \mathrm{Sb} 5 / \mathrm{K} / \mathrm{d}$ for 20 days, as established by $\mathrm{MOH}$ Colombia guidelines.

Statistical analysis: Data entry and analysis were performed using ACCESS and SPSS version 15, respectively. Participant characteristics were tabulated and analyzed by treatment group. The efficacy of treatments was calculated by intention to treat and by protocol. The relative risk was calculated using 2 × 2 tables. The $X^{2}$ test or Fisher's 


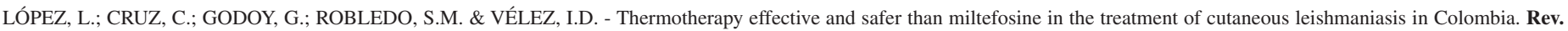
Inst. Med. Trop. Sao Paulo, 55(3): 197-204, 2013.

exact test were used for hypothesis testing on dichotomous variables. Taking into account the distribution of variables, the Student's t-test or Mann-Whitney U-test were used to analyze continuous data. Potential confounding factors and interactions were controlled using a stratified analysis of species of the parasite responsible for the infection, number, anatomical location, type of lesion, and geographical location of the infection. Survival analysis methods (Kaplan-Meier and Log-rank test) were used to compare disease-free times between the two treatments. A $p<0.05$ was considered significant for all analyses, and a confidence of $95 \%$ was used for the construction of all intervals.

\section{RESULTS}

There were 294 patients who accepted voluntary participation and were included in the study and randomly assigned; 145 received miltefosine and 149 received thermotherapy. In the miltefosine group, two patients (1\%) did not complete treatment due to side effects, and 21 (14\%) were lost by the 6-month follow-up; for this reason, at the end, only $122(84 \%)$ completed the study. In the thermotherapy group, two patients $(1 \%)$ decided not to participate in the study after randomization, 18 (13\%) were lost by the 6-month follow-up, and 134 (90\%) completed the study (Fig. 1).

Baseline analysis: As observed in Table 1, the demographic, clinical, and parasitological characteristics of the participants were similar between both study groups, except for type of lesion.

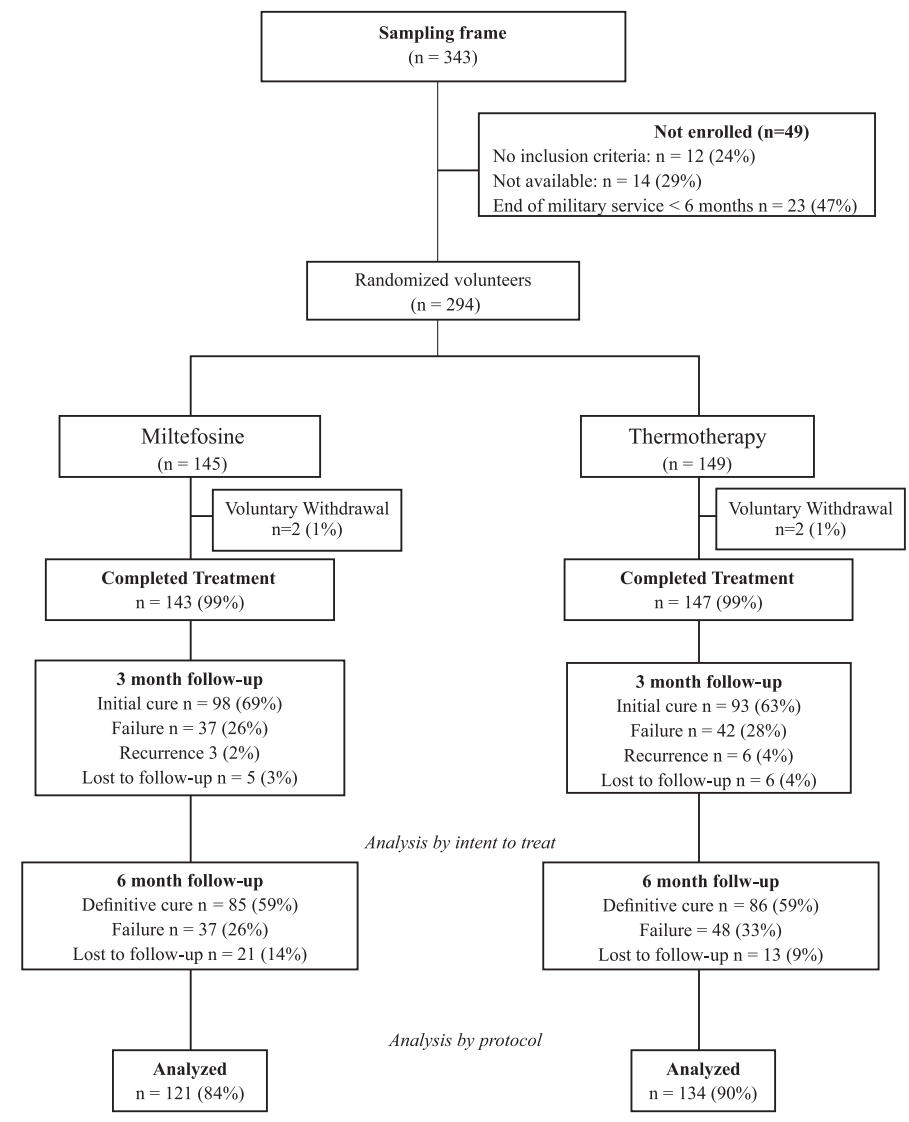

Fig. 1 - Flow diagram of the volunteer study participants.

\section{Therapeutic response}

Initial cure: Three months after completion of treatment, $98(68.5 \%)$ and $93(63.2 \%)$ of the patients treated with miltefosine and thermotherapy were cured, respectively.

Definitive cure: the number of patients who were cured is shown in Table 2, which is organized by treatment and by type of analysis.

At six months after completion of treatment, 85 (69.5\%) and 86 $(64.5 \%)$ of the volunteers receiving miltefosine and thermotherapy, respectively, had a complete cure from all lesions (analysis by protocol). By intention to treat, the efficacy was $59.4 \%$ for the group that received miltefosine and $58.5 \%$ for the group treated with thermotherapy. There were not found differences between the scars of patients who received miltefosine or thermotherapy.

Analysis by group: In 164 (56\%) patients, the Leishmania species responsible for infection was isolated and identified; 81 of the patients were treated with miltefosine, in whom $30(37 \%)$ and $51(63 \%)$ of the isolated strains were identified as $L$. (V.) panamensis and L. (V.) braziliensis, respectively. Of the group treated with thermotherapy, the strain was identified in 83 patients, in whom $24(29 \%)$ and $59(71 \%)$ of the strains were $L$. (V.) panamensis and $L$. (V.) braziliensis, respectively.

Cure rates in the miltefosine group were $60 \%$ for $L .(V$.) panamensis and $49 \%$ for $L$. (V.) braziliensis. The cure rate for the thermotherapy group was $58 \%$ for $L$. (V.) panamensis and $53 \%$ for $L$. (V.) braziliensis. No significant difference was found for treatment efficacy between the species responsible for infection (miltefosine $p=0.3$, thermotherapy $p=0.6)$.

Also, there was no association found between treatment efficacy and characteristics, such as number, anatomical location, lesion type, or geographical location in Colombia where the infection occurred (Table 3).

Recurrence: Three $(2.1 \%)$ and six $(4.1 \%)$ of the patients treated with miltefosine and thermotherapy, respectively, had recurrences.

Safety: Localized and systemic adverse events seen in our study are summarized in Table 4.

Mid-way through treatment, miltefosine was associated with a greater occurrence of headache, vomiting, nausea, and anorexia, and at the end of treatment with a greater frequency of myalgia, arthralgia, headache, vomiting, nausea, and anorexia. Thermotherapy was associated with pain at the lesion site following the application of treatment.

We were able to determine that there is no association of either of the two treatments with changes in renal (Creatinine and BUN), hepatic (AST and ALT), and blood (hemoglobin, hematocrit, erythrocytes, leukocytes, and platelets) tests, neither mid-way through the treatment nor at the end. However, the proportion of changes in lab results for hepatic and pancreatic tests was greater in the miltefosine group.

Serious adverse events: One volunteer from the miltefosine group developed hematemesis, which was medically treated until the patient's recovery. 
LÓPEZ, L.; CRUZ, C.; GODOY, G.; ROBLEDO, S.M. \& VÉLEZ, I.D. - Thermotherapy effective and safer than miltefosine in the treatment of cutaneous leishmaniasis in Colombia. Rev. Inst. Med. Trop. Sao Paulo, 55(3): 197-204, 2013.

Table 1

Baseline characteristics of volunteers

\begin{tabular}{|c|c|c|c|c|}
\hline Characteristics & & $\begin{array}{c}\text { miltefosine } \\
n=145\end{array}$ & $\begin{array}{c}\text { Thermotherapy } \\
\text { n= } 149\end{array}$ & $p$-value $*$ \\
\hline Age (years) (Median [min - max]) & & $23(19-37)$ & $23(19-39)$ & $0.9^{\dagger}$ \\
\hline Race (\%) & $\begin{array}{l}\text { White } \\
\text { Black } \\
\text { Mestizo }^{\ddagger} \\
\text { Mulatto }^{\S}\end{array}$ & $\begin{array}{c}14(10) \\
9(6) \\
116(80) \\
6(4) \\
\end{array}$ & $\begin{array}{c}22(14) \\
13(9) \\
104(70) \\
10(7) \\
\end{array}$ & 0.25 \\
\hline Weight $(\mathrm{Kg})($ Median $[\min -\max ])$ & & $64(47-90)$ & $65(42-104)$ & $0.8^{\dagger}$ \\
\hline History of leishmaniasis (\%) & $\begin{array}{l}\text { Yes } \\
\text { No }\end{array}$ & $\begin{array}{l}63(43) \\
82(57) \\
\end{array}$ & $\begin{array}{l}67(45) \\
82(55) \\
\end{array}$ & 0.79 \\
\hline Geographical place of infection & $\begin{array}{l}\text { Northeast } \\
\text { Southeast }\end{array}$ & $\begin{array}{c}15(10) \\
130(90) \\
\end{array}$ & $\begin{array}{c}16(11) \\
133(89) \\
\end{array}$ & 0.91 \\
\hline Number of lesions $(\%)^{* *}$ & $\begin{array}{l}1 \\
2 \text { or more }\end{array}$ & $\begin{array}{l}101(70) \\
44(30) \\
\end{array}$ & $\begin{array}{l}115(77) \\
34(23) \\
\end{array}$ & 0.14 \\
\hline Type of lesion (\%) & $\begin{array}{l}\text { Nodule } \\
\text { Ulcer }\end{array}$ & $\begin{array}{c}9(5) \\
182(95) \\
\end{array}$ & $\begin{array}{c}19(11) \\
161(89) \\
\end{array}$ & 0.04 \\
\hline Anatomical location of lesion & $\begin{array}{l}\text { Upper body } \\
\text { Lower body }^{\#}\end{array}$ & $\begin{array}{l}117(81) \\
28(19) \\
\end{array}$ & $\begin{array}{c}123(83) \\
26(17) \\
\end{array}$ & 0.68 \\
\hline Evolution time (days) (Median [min $-\max ])$ & & $60(15-1080)$ & $85(10-690)$ & $0.7^{\dagger}$ \\
\hline Species $(\%)$ & $\begin{array}{l}\text { L. (V.) panamensis } \\
\text { L. (V.) braziliensis }\end{array}$ & $\begin{array}{l}30(37) \\
51(63) \\
\end{array}$ & $\begin{array}{l}24(29) \\
59(71) \\
\end{array}$ & 0.27 \\
\hline
\end{tabular}

* Chi square test; ${ }^{\dagger}$ Mann Whitney test; ${ }^{\dagger}$ person who is born from one white parent and one indian parent; ${ }^{\S}$ person who is born from one white parent and one black parent; ** According to number of lesions;: This category includes 18 volunteers who presented with lesions to the upper and lower body; 8 and 10 from the miltefosine and thermotherapy groups, respectively

Table 2

Efficacy of miltefosine and thermotherapy. Analysis by protocol and by intention to treat

\begin{tabular}{|c|c|c|c|c|c|}
\hline \multirow{2}{*}{ Analysis } & \multicolumn{2}{|c|}{ Miltefosine } & \multicolumn{2}{|c|}{ Thermotherapy } & \multirow{2}{*}{$p$-value* } \\
\hline & Cure / Total & Efficacy (\%) CI 95\% & Cure / Total & Efficacy (\%) CI 95\% & \\
\hline Intention to treat & $85 / 145$ & $59(50-67)$ & $86 / 149$ & $58(49-66)$ & 0.9 \\
\hline By protocol & $85 / 122$ & $70(61-78)$ & $86 / 134$ & $64(55-73)$ & 0.4 \\
\hline
\end{tabular}

*Chi square test.

Survival analysis: The time free of disease for both treatments is shown in Figure 2. No difference was found between the cumulative survival rates of patients who received miltefosine and those who received thermotherapy $(p=0.2)$.

\section{DISCUSSION}

The efficacy of miltefosine, $70 \%$ by intention to treat and $59 \%$ per protocol, differs with previous studies conducted in Colombia where the efficacy of the protocol was $91 \%$, but it is similar to that found in Guatemala where it was $53 \%$.

The differences in therapeutic response in the previous study in Colombia and Guatemala were attributed to the species of Leishmania predominant in each country ${ }^{22}$. The data for Colombia, however, was mainly based on historical records, given that only seven isolated strains were identified in the study from the 73 study participants, and all were identified as $L$. $(V$.) panamensis. In this study, we included a larger number of patients than previous studies. Additionally, both species of Leishmania causing the majority of leishmaniasis cases in the country were present, and there were no significant differences in treatment response between the species responsible for the infection. However, we did observe a decreased therapeutic response in patients with $L$. (V.) braziliensis, of whom $49 \%$ were cured versus $53 \%$ of patients with $L$. (V.) panamensis. A similar situation was observed for thermotherapy treatment.

Thermotherapy showed an efficacy of $58 \%$ and $64 \%$ in the analysis by intention to treat and by protocol, respectively. This result was comparable to that obtained in Kabul, Afghanistan, where the efficacy by protocol was found to be $69.4 \%{ }^{19}$ and less than that found in other studies where localized heat was applied in various dosages.

The Thermomed ${ }^{\circledR}$ equipment gives and maintains localized heat of 50 degrees Celsius at the application site ${ }^{1}$ and has the advantage of being completed in one to four sessions, decreasing the adherence problems faced by other treatments. Also, it does not have systemic side effects, so 


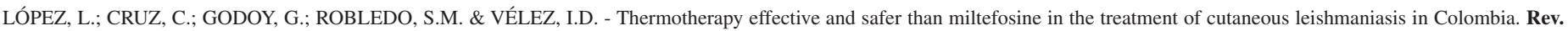
Inst. Med. Trop. Sao Paulo, 55(3): 197-204, 2013.

Table 3

Efficacy of miltefosine and thermotherapy stratified by parasite species, anatomical location, number and type of lesion, and geographical location of infection

\begin{tabular}{|c|c|c|c|c|}
\hline \multirow{2}{*}{ Characteristics } & Efficacy/total volunteers (\%) & \multirow{2}{*}{$p$-value** } & Efficacy/total volunteers (\%) & \multirow{2}{*}{$p$-value** } \\
\hline & Miltefosine & & Thermotherapy & \\
\hline Overall efficacy & $85 / 145(59)$ & - & $86 / 149(58)$ & - \\
\hline \multicolumn{5}{|c|}{ History of leishmaniasis } \\
\hline Yes & $45 / 63(71)$ & \multirow{2}{*}{0.04} & $45 / 67(67)$ & \multirow{2}{*}{0.05} \\
\hline No & $39 / 82(48)$ & & $42 / 82(51)$ & \\
\hline \multicolumn{5}{|l|}{ Species } \\
\hline L. (V.) panamensis & $18 / 30(60)$ & \multirow[t]{2}{*}{0.3} & $14 / 24(58)$ & \multirow[t]{2}{*}{0.6} \\
\hline L. (V.) braziliensis & $25 / 51(49)$ & & $31 / 59(53)$ & \\
\hline \multicolumn{5}{|l|}{ Number of lesions } \\
\hline 1 & $60 / 101(59)$ & \multirow[t]{2}{*}{0.5} & $70 / 115(61)$ & \multirow[t]{2}{*}{0.3} \\
\hline 2 or more & $24 / 44(55)$ & & $17 / 34$ & \\
\hline \multicolumn{5}{|c|}{ Anatomical location of lesions } \\
\hline Upper body & $66 / 117(56)$ & \multirow[t]{2}{*}{0.4} & $73 / 123(59)$ & \multirow[t]{2}{*}{0.6} \\
\hline Lower body ${ }^{\dagger}$ & $18 / 28(64)$ & & $14 / 26(54)$ & \\
\hline \multicolumn{5}{|c|}{ Geographical place of infection } \\
\hline Northeast & $10 / 15(67)$ & 0.5 & $6 / 16(38)$ & \multirow{2}{*}{0.08} \\
\hline$\underline{\text { Southeast }}$ & $74 / 130(57)$ & & $81 / 133(60)$ & \\
\hline
\end{tabular}

** Chi square test; ${ }^{\dagger}$ This category includes 18 volunteers who presented with lesions on the upper and lower parts of the body; 8 and 10 from the miltefosine and thermotherapy groups, respectively.

Table 4

Incidence and relative risk of local and systemic adverse events presented at the end and middle of treatment

\begin{tabular}{|c|c|c|c|c|c|c|c|}
\hline \multirow[t]{2}{*}{ Test/Event } & & \multicolumn{2}{|c|}{ Middle of treatment } & \multirow[t]{2}{*}{ RR (CI 95\%) } & \multicolumn{2}{|c|}{$\begin{array}{l}\text { End of treatment } \\
\text { Event or Test/Total volunteers }(\%)\end{array}$} & \multirow[t]{2}{*}{ RR (CI 95\%) } \\
\hline & & Miltefosine & Thermotherapy & & Miltefosine & Thermotherapy & \\
\hline \multirow{13}{*}{ 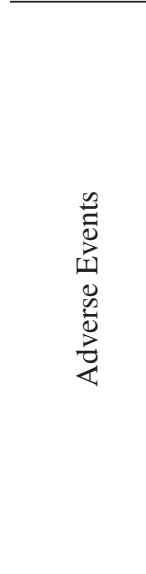 } & Fever & $8 / 130(6)$ & $4 / 124(3.22 \%)$ & $1.91(0.59-6.18)$ & $8 / 129(6)$ & $4 / 132(3)$ & $2.05(0.63-6.63)$ \\
\hline & Myalgia & $9 / 130(7)$ & $3 / 124(2.41 \%)$ & $2.86(0.79-10.33)$ & $16 / 129(12)$ & $4 / 132(3)$ & $4.1(1.41-11.91)^{*}$ \\
\hline & Arthralgia & $9 / 130(7)$ & $3 / 124(2.41 \%)$ & $2.86(0.79-10.33)$ & $13 / 129(10)$ & $3 / 132(2)$ & $4.43(1.29-15.2)^{*}$ \\
\hline & Headache & 23/130 (18) & $10 / 124(8.1 \%)$ & $2.19(1.09-4.42)$ & $30 / 129(23)$ & $13 / 132(10)$ & $2.36(1.29-4.32)^{*}$ \\
\hline & Vomiting & $29 / 130(22)$ & $3 / 124(2.41 \%)$ & $9.22(2.88-29.50)^{* *}$ & $44 / 129(34)$ & $2 / 132(2)$ & $22.51(5.57-90.9)^{* *}$ \\
\hline & Nausea & $38 / 130(29)$ & $5 / 124(4.03 \%)$ & $7.25(2.95-17.82)^{* *}$ & $59 / 129(46)$ & $4 / 132(3)$ & $15.1(5.65-40.34) * *$ \\
\hline & Anorexia & $19 / 130(11)$ & $5 / 124(4.03 \%)$ & $3.62(1.40-9.41)^{*}$ & $37 / 129(29)$ & $6 / 132(5)$ & $6.31(2.76-14.44) * *$ \\
\hline & Diarrhea & $0 / 130(0)$ & $0 / 124(0 \%)$ & - & $6 / 129(5)$ & $1 / 132(2)$ & $6.14(0.75-50.29)$ \\
\hline & Abdominal pain & $0 / 130(0)$ & $0 / 124(0)$ & - & $9 / 129(7)$ & $0 / 132(0)$ & - \\
\hline & Lesion pain & $14 / 130(9)$ & $27 / 124(22)$ & & $11 / 129(9)$ & 18/132 (14) & $0.63(0.31-1.27)$ \\
\hline & Lesion infection & $5 / 130(4)$ & $9 / 124(7)$ & $0.53(0.18-1.54)$ & $5 / 129(4)$ & $11 / 132(8)$ & $0.47(0.17-1.3)$ \\
\hline & Lesion vesicles & $0 / 130(0)$ & $4 / 124(3)$ & - & $0 / 129(0)$ & $5 / 132(4)$ & - \\
\hline & Pruritus & $0 / 130(0)$ & $0 / 124(0)$ & - & $3 / 125(2)$ & $4 / 125(3)$ & $0.75(0.17-3.28)$ \\
\hline \multirow{5}{*}{ 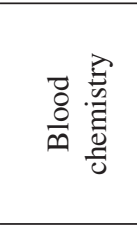 } & $\uparrow$ Creatinine & - & - & - & $1 / 103(2)$ & $0 / 80(0)$ & - \\
\hline & $\uparrow \mathrm{BUN}$ & - & $1 / 83(2)$ & - & $3 / 103(3)$ & $2 / 80(3)$ & $1.17(0.2-6.81)$ \\
\hline & $\uparrow \mathrm{AST}$ & $1 / 114(2)$ & $1 / 93(2)$ & $0.82(0.05-12.98)$ & $5 / 103(5)$ & $2 / 75(2.67)$ & $1.82(0.36-9.13)$ \\
\hline & $\uparrow$ ALT & $1 / 114(2)$ & $1 / 93(2)$ & $0.82(0.05-12.87)$ & $10 / 104(10)$ & $5 / 73(6.84)$ & $1.4(0.5-3.94)$ \\
\hline & $\uparrow$ Amylase & $15 / 111(14)$ & $6 / 87(7)$ & $1.96(0.79-4.84)$ & $11 / 102(7)$ & $7 / 70(10)$ & $1.08(0.44-2.65)$ \\
\hline \multirow{4}{*}{ 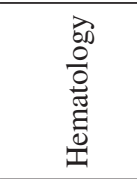 } & $\downarrow$ Hemoglobin & - & - & - & $1 / 102(2)$ & $1 / 78(1.28)$ & $0.76(0.05-12.04)$ \\
\hline & $\downarrow$ Erythrocytes & $1 / 105(2)$ & $4 / 82(5)$ & $0.20(0.02-1.71)$ & $1 / 102(2)$ & $1 / 75(1.33)$ & $0.74(0.05-11.57)$ \\
\hline & $\downarrow$ Leukocytes & $2 / 115(2)$ & $0 / 96(0)$ & - & $1 / 105(2)$ & $0 / 79(0)$ & - \\
\hline & $\downarrow$ Platelets & - & - & - & - & $1 / 79(1.27)$ & - \\
\hline
\end{tabular}

$*<0.05 ; * *<0.001$. 


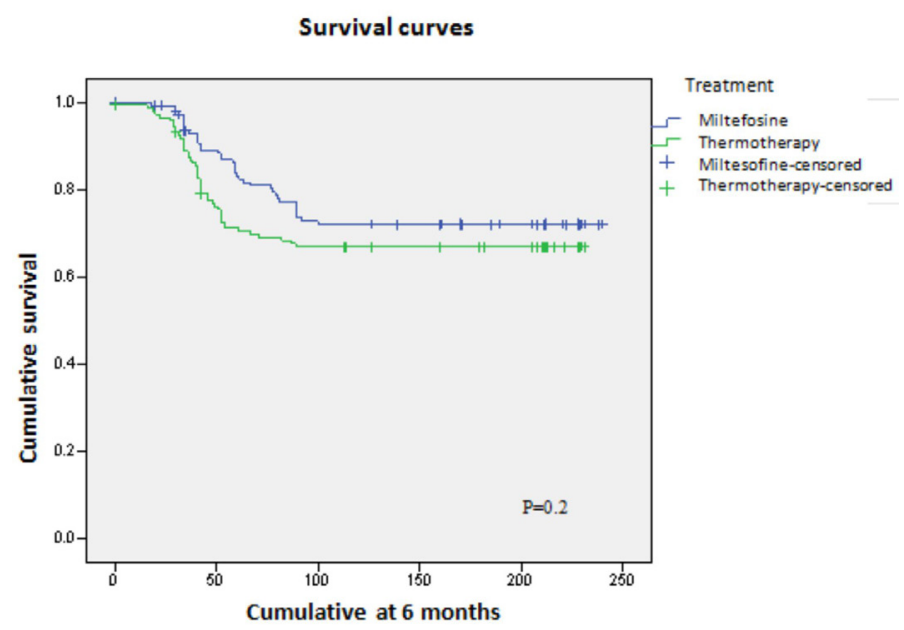

Fig. 2 - Cumulative survival estimates for absence of disease for each treatment.

it does not require paraclinical analysis, patients need not be in treatment or in convalescence for extended periods of time, and it can also be used in patients with renal, hepatic, or cardiac alterations, as well as in women who are pregnant, breastfeeding, or of child-bearing age, all of whom are disqualified from conventional treatment with pentavalent antimonials or miltefosine.

In addition, ethno-medical studies in indigenous and farming communities in Latin America show extensive and empirical use of locally applied caustic agents (gunpowder, hot sugar cane, silver nitrate, petroleum, and battery acid) or cauterization with hot metallic instruments, such as spoons or the edge of an ax, which they apply over the lesions, achieving, in many cases, lesion scarring ${ }^{14,33,34}$.

The association between miltefosine and gastrointestinal adverse events, such as nausea, vomiting, anorexia, abdominal pain, and diarrhea, reported in previous studies was confirmed ${ }^{24,32}$. With respect to safety in the thermotherapy group, the only reported adverse event was pain at the site of heat application, which was controlled with common analgesics and did not persist for longer than one week after heat application.

In India, Miltefosine is the first oral agent that has shown a good efficacy for the treatment of visceral leishmaniasis caused by $L$. (L.) donovani, or Kala-azar. However, it's use for CL treatment in the New World is limited. Some of its inconveniences are as follows: current cost (about 670 USD), which is greater than that of antimonials, long treatment period (28 days) leading to adherence problems, lack of adherence leading to strain resistance, teratogenicity, which complicates its administration to women of child-bearing age because adequate contraception must be guaranteed during treatment and up to three months after treatment, gastrointestinal adverse effects in over $30 \%$ of patients, and finally, as seen in this study, efficacy inferior to that of pentavalent antimonials, which continue to have an efficacy rate of $85.1 \%$ in Colombia ${ }^{32}$.

The results of this study show that the efficacy of thermotherapy in single doses is similar to that of oral miltefosine with a duration of 28 days for the treatment of CL in Colombia ( $p=0.9$ ), and its toxicity is lower.

One of the criticisms against the use of local therapy in the treatment of patients with CL caused by species of the Viannia subgenre is the possibility of developing ML. In the case of Colombia, the necessity for prescribing systemic treatment to all patients is debatable, given that the incidence of ML in the country is less than $0.5 \%$, despite the fact that the great majority of patients with CL who reside in rural areas far away from a health care center are empirically treated with caustic agents. In these populations, it is estimated that only $10 \%$ of patients with CL receive treatment with antimonials, and even then, the incidence of ML is very low. In addition, systemic treatment does not guarantee the absence of $\mathrm{ML}^{14,33,34,35}$.

However, the cure rate seen in our study with one dose of thermotherapy is not sufficiently large enough to recommend it as treatment. In the clinical studies where greater cure rates have been seen, the patients received two or three heat therapy sessions.

We believe that further clinical studies should be conducted with thermotherapy using an increased number of heat application sessions or in combination with other local medications.

In American CL, the dissemination of parasites through the lymphatic system happens early at the beginning of the lesion. In patients with less than three months of disease evolution, $90 \%$ present with lymphadenopathies; however, ML cases are rare. In any case, all local treatments should be accompanied by patient education regarding early detection of lesion reactivation signs and possible mucosal complications so that they may consult their physician and reserve systemic treatments for these cases.

\section{FUNDING}

This study was financed by the Ministry of Social Protection of the Republic of Colombia, which did not participate in the design, execution, or report.

\section{CONFLICTS OF INTEREST}

None declared.

\section{ETHICAL APPROVAL}

The protocol was approved by the Committee of Bioethics for human research of the University Research Headquarters (CBEIH-SIU) of the University de Antioquia and by the Ethics Committee of the Directorate General of Health of the Colombian army. The clinical trial was developed following the international guidelines for good clinical practice (GCP).

\section{RESUMEN}

\section{Termoterapia efectiva y más segura que la miltefosina en el tratamiento de la leishmaniasis cutánea en Colombia}

En Colombia antimoniales pentavalentes y miltefosina son los medicamentos de primera elección para el tratamiento de la leishmaniosis cutánea; sin embargo, su toxicidad, duración (que lleva a problemas de adherencia), costo y la disminución de la sensibilidad de los parásitos a los mismos, hacen necesaria la búsqueda de nuevas alternativas de tratamiento para la leishmaniosis cutánea americana. A partir de resultados derivados de un ensayo clínico controlado abierto, 
LÓPEZ, L.; CRUZ, C.; GODOY, G.; ROBLEDO, S.M. \& VÉLEZ, I.D. - Thermotherapy effective and safer than miltefosine in the treatment of cutaneous leishmaniasis in Colombia. Rev. Inst. Med. Trop. Sao Paulo, 55(3): 197-204, 2013.

aleatorizado, fase III, se comparó la eficacia y seguridad de la miltefosina con la de la termoterapia, para el tratamiento de la leishmaniosis cutánea en Colombia. Adultos pertenecientes al Ejército de Colombia participaron el estudio. Miltefosina, una cápsula de $50 \mathrm{mg}$ tres veces día durante 28 días, vía oral $(n=145)$. Termoterapia $\left(\right.$ Thermomed $\left.^{\circledR}\right)$ aplicación de $50^{\circ} \mathrm{C} / 30^{\prime \prime}$ sobre la lesión y el área circundante $(\mathrm{n}=149)$. Ambos grupos fueron comparables en características sociodemográficas, clínicas y parasitológicas. Eficacia de la miltefosina por protocolo $70 \%$ $(85 / 122$ pacientes) y $69 \%$ (85/145 pacientes) por intención a tratar. Termoterapia eficacia por protocolo $64 \%$ (86/134 pacientes) y $58 \%$ (86/149 pacientes) por intención a tratar. En miltefosina los eventos adversos fueron principalmente de tipo gastrointestinal y en termoterapia se encontró dolor en el sitio de la lesión luego del tratamiento. En el análisis de eficacia (intención a tratar y protocolo) no se encontró diferencia estadísticamente significativa entre los tratamientos evaluados. ClinicalTrials.gov: NCT00471705.

\section{ACKNOWLEDGEMENTS}

The authors thank the Ministry of Social Protection, especially Dr. Julio Cesar Padilla for his support and co-financing of the study, and the Colombia army personnel led by General Mario Montoya Uribe, who supported and made possible the conduction of the study. We thank the personnel of the Directorate of Health of the Army, especially Coronel Fernando Pineda Solarte, TC David Rojas Tirado, and the team of dermatologists of the army TC Alvaro Sandoval, TC Gustavo Pérez, TC Margarita Vargas, and TC Martha Robayo for their support of this study. We thank the personnel of the PECET for their collaboration, especially Carlos Muskus, Eugenia Cardona, Daniel Agudelo and Ronald Peláez, as well as Dr. María Patricia Arbeláez for her advice in the design and analysis of the study. We also wish to express our gratitude to all of the patients for their availability and commitment to the study.

\section{REFERENCES}

1. Adams E. Thermosurgery in dermatology. Boston: Technology Assessment Program, Office of Patient Care Services; 2008.

2. Bailey MS, Lockwood DN. Cutaneous leishmaniasis. Clin Dermatol. 2007;25:203-11.

3. Bari AU, Rahman SB. A therapeutic update on cutaneous leishmaniasis. J Coll Physicians Surg Pak. 2003;13:471-6.

4. Bejarano EE, Sierra D, Perez-Doria A, Velez ID. Primer hallazgo de Lutzomyia tihuiliensis (Diptera: Psychodidae) en el Valle de Aburra, Colombia. Biomedica. 2006;26(Suppl 1):228-31.

5. Croft SL, Snowdon D, Yardley V. The activities of four anticancer alkyllysophospholipids against Leishmania donovani, Trypanosoma cruzi and Trypanosoma brucei. J Antimicrob Chemother. 1996;38:1041-7.

6. Escobar P, Matu S, Marques C, Croft SL. Sensitivities of Leishmania species to hexadecylphosphocholine (miltefosine), ET-18-OCH(3) (edelfosine) and amphotericin B. Acta Trop. 2002;81:151-7.

7. Escobar P, Yardley V, Croft SL. Activities of hexadecylphosphocholine (miltefosine), AmBisome, and sodium stibogluconate (Pentostam) against Leishmania donovani in immunodeficient scid mice. Antimicrob Agents Chemother. 2001;45:1872-5.

8. Gonzalez U, Pinart M, Rengifo-Pardo M, Macaya A, Alvar J, Tweed JA. Interventions for American cutaneous and mucocutaneous leishmaniasis. Cochrane Database Syst Rev. 2009;15:CD004834
9. Hendrickx EP, Agudelo SP, Munoz DL, Puerta JA, Velez Bernal ID. Lack of efficacy of mefloquine in the treatment of New World cutaneous leishmaniasis in Colombia. Am J Trop Med Hyg. 1998;59:889-92.

10. Levine N. Cutaneous leishmaniasis treated with controlled localized heating. Arch Dermatol. 1992;128:759-61.

11. López L, Robayo M, Vargas M, Vélez I. Thermotherapy. An alternative for the treatment of American cutaneous leishmaniasis. Trials. 2012:13:58.

12. Momeni AZ, Aminjavaheri M, Omidghaemi MR. Treatment of cutaneous leishmaniasis with ketoconazole cream. J Dermatolog Treat. 2003;14:26-9.

13. Montalvo AM, Monzote L, Fraga J, Montano I, Muskus C, Marin M, et al. RFLP y RAPD para la tipificación de Leishmania neotropical. Biomedica. 2008;28:597-606.

14. Moreira R da C, Rebelo JM, Gama ME, Costa JM. Nível de conhecimentos sobre Leishmaniose Tegumentar Americana (LTA) e uso de terapias alternativas por populações de uma área endêmica da Amazônia do Maranhão, Brasil. Cad Saude Publica. 2002;18:187-95

15. Nakayama H, Loiseau PM, Bories C, Torres de Ortiz S, Schinini A, Serna E, et al. Efficacy of orally administered 2-substituted quinolines in experimental murine cutaneous and visceral leishmaniases. Antimicrob Agents Chemother. 2005;49:4950 6.

16. Navin TR, Arana BA, Arana FE, de Merida AM, Castillo AL, Pozuelos JL. Placebocontrolled clinical trial of meglumine antimonate (glucantime) vs. localized controlled heat in the treatment of cutaneous leishmaniasis in Guatemala. Am J Trop Med Hyg 1990;42:43-50.

17. Neuber H. Leishmaniasis. J Dtsch Dermatol Ges. 2008:6:754-65.

18. Osorio LE, Palacios R, Chica ME, Ochoa MT. Treatment of cutaneous leishmaniasis in Colombia with dapsone. Lancet. 1998;351:498-9.

19. Reithinger R, Mohsen M, Wahid M, Bismullah M, Quinnell RJ, Davies CR, et al. Efficacy of thermotherapy to treat cutaneous leishmaniasis caused by Leishmania tropica in Kabul, Afghanistan: a randomized, controlled trial. Clin Infect Dis. 2005;40:1148-55.

20. Robinson RJ, Agudelo S, Muskus C, Alzate JF, Berberich C, Barker DC, Velez ID The method used to sample ulcers influences the diagnosis of cutaneous leishmaniasis. Trans R Soc Trop Med Hyg. 2002;96(Suppl 1):S169-71.

21. Singh S, Singh R, Sundar S. Failure of ketoconazole treatment in cutaneous leishmaniasis. Int J Dermatol. 1995;34:120-1.

22. Soto J AB, Arana AB, Toledo J, Rizzo N, Vega JC, Diaz A, et al. Miltefosine for new world cutaneous leishmaniasis. Clin Infect Dis. 2004;38:1266-72.

23. Soto J, Toledo J, Gutierrez P, Nicholls RS, Padilla J, Engel J, et al. Treatment of American cutaneous leishmaniasis with miltefosine, an oral agent. Clin Infect Dis. 2001;33:E57-61.

24. Sundar S, Jha JT, Thakur CP, Engel J, Sindermann H, Fischer C, et al. Oral miltefosine for Indian visceral leishmaniasis. N Engl J Med. 2002;347:1739-46.

25. Sundar S, Rosenkaimer F, Makharia MK, Goyal AK, Mandal AK, Voss A, et al. Trial of oral miltefosine for visceral leishmaniasis. Lancet. 1998;352:1821-3.

26. Trotti A, Colevas AD, Setser A, Rusch V, Jaques D, Budach V, et al. CTCAE v3.0: development of a comprehensive grading system for the adverse effects of cancer treatment. Semin Radiat Oncol. 2003;13:176-81.

27. Tuon FF, Amato VS, Graf ME, Siqueira AM, Nicodemo AC, Amato Neto V. Treatment of New World cutaneous leishmaniasis--a systematic review with a meta-analysis. Int J Dermatol. 2008;47:109-24. 
LÓPEZ, L.; CRUZ, C.; GODOY, G.; ROBLEDO, S.M. \& VÉLEZ, I.D. - Thermotherapy effective and safer than miltefosine in the treatment of cutaneous leishmaniasis in Colombia. Rev. Inst. Med. Trop. Sao Paulo, 55(3): 197-204, 2013.

28. Unger C, Damenz W, Fleer EA, Kim DJ, Breiser A, Hilgard P, et al. Hexadecylphosphocholine, a new ether lipid analogue. Studies on the antineoplastic activity in vitro and in vivo. Acta Oncol. 1989;28:213-7.

29. Vega JC, Sanchez BF, Montero LM, Montana R, Mahecha M del P, Dueñes B, et al. The efficacy of thermotherapy to treat cutaneous leishmaniasis in Colombia: a comparative observational study in an operational setting. Trans R Soc Trop Med Hyg. 2009;103:703-6.

30. Velasco-Castrejon O, Walton BC, Rivas-Sanchez B, Garcia MF, Lazaro GJ, Hobart $\mathrm{O}$, et al. Treatment of cutaneous leishmaniasis with localized current field (radio frequency) in Tabasco, Mexico. Am J Trop Med Hyg 1997;57:309-12.

31. Velez I, Agudelo S, Hendrickx E, Puerta J, Grogl M, Modabber F, et al. Inefficacy of allopurinol as monotherapy for Colombian cutaneous leishmaniasis. A randomized, controlled trial. Ann Intern Med. 1997;126:232-6.

32. Velez I, Lopez L, Sanchez X, Mestra L, Rojas C, Rodriguez E. Efficacy of miltefosine for the treatment of American cutaneous leishmaniasis. Am J Trop Med Hyg. 2010;83:351-6
33. Velez ID, Hendrickx E, Robledo SM, del Pilar Agudelo S. Leishmaniosis cutánea en Colombia y género. Cad Saude Publica. 2001;17:171-80.

34. Weigel MM, Armijos RX. The traditional and conventional medical treatment of cutaneous leishmaniasis in rural Ecuador. Rev Panam Salud Publica. 2001;10:395404.

35. World Health Organization. Control of the leishmaniasis. Geneva, WHO; 2010.

36. World Health Organization. Division of Control of Tropical Diseases (TDR) Leishmaniasis control home page. [cited: 2009, June 24]. Available from: http:// www.who.int/neglected_diseases/integrated_media_leishmaniasis.

37. Yardley V, Croft SL, De Doncker S, Dujardin JC, Koirala S, Rijal S, et al. The sensitivity of clinical isolates of Leishmania from Peru and Nepal to miltefosine. Am J Trop Med Hyg. 2005;73:272-5.

Received: 26 June 2012

Accepted: 12 November 2012 